8. Spector, A. A., John, K., and Fletcher, J. E.: Binding of long-chain fatty acids to bovine serum albumin. J. Lipid Res., 10: 56 (1969).

9. Wright, E. M., and Diamond, J. M.: Patterns of non-electrolyte permeability. Proc. Roy. Soc. Ser. B., 172: 227 (1969).

10. State College, $\mathrm{Pa}$.

11. Boston, Mass.

12. St. Louis, Mo.

13. We wish to thank Dr. William Rosner for valuable discussion and advice.
14. Dr. J. Dancis is a Career Investigator, National Institute of Child Health and Development, National Institutes of Health, Bethesda, Md.

15. This study was supported by Grants nos. HDO-0462 and CA 02071, National Institutes of Health, Bethesda, Md.

16. Requests for reprints should be addressed to: J. Dancis, M.D., Department of Pediatrics, New York University, Medical Center, School of Medicine, 550 1st Ave., New York, N. Y. 10016 (USA).

17. Accepted for publication August 15, 1975

\title{
Behavioral and Biochemical Correlates of Diet Change in Phenylketonuria
}

\author{
V. ELVING ANDERSON ${ }^{(60)}$ AND FELICIA S. SIEGEL \\ Dight Institute for Human Genetics, University of Minnesota, Minneapolis, Minnesota, USA
}

HEINZ H. BRUHL

Faribault State School and Hospital, Faribault, Minnesota, USA

\section{Extract}

The investigation was designed to explore the use of tests tapping reversible aspects of behavior and performance and to find out whether these data can be correlated with concurrent metabolic changes in different dietary phases. The four subjects had classic phenylketonuria, diagnosed on the basis of a high level of serum phenylalanine on a regular diet, and severe mental retardation. Three types of diet were used: the general institutional diet, a low phenylalanine diet, and a low phenylalanine diet with added L-phenylalanine. A position discrimination and reversal task was used. Blood samples were taken every week on the day before psychological testing, and one 24-hr urine sample was collected during each dietary phase.

In subjects $I$ and $I I$ performance deteriorated upon elevation of the serum phenylalanine level, but these changes were transient only, thus showing an adaptation to the effects of the high serum phenylalanine level.

Subject $I I I$ showed increased response latencies (slower test responses) during high phenylalanine diet phases and faster responses while on a low phenylalanine diet. The correlation between response time and phenylalanine level is highly significant $(r=0.86$, $P<0.001$ ).

On the low phenylalanine diet subject $I V$ 's responses were fast and her performance was very stable, which contrasted with erratic performance during the high phenylalanine phases. Calculations show a significant association with phenylalanine level, both for response time $(r=0.47, P<0.05)$ and for variability in response time within each session $(r=0.46, P<0.05)$.

Biochemical variability was observed in metabolic responses to phenylalanine loading, especially in the excretion of tryptophan metabolites.

\section{Speculation}

A simultaneous analysis of biochemical and behavioral parameters in sufficient detail to permit the detection of individual variability is shown to be feasible. Further studies of a similar nature on a larger scale should help to achieve a more precise understanding of the biochemical processes in the nervous system which are responsible for the behavioral changes.

Clinical observations $(9,18,19,55,56)$ suggest that phenylketonuria (PKU) produces two effects on the individual: (1) a permanent effect upon the developing brain, and (2) "toxic" effects upon somatic and central nervous system functions which are responsive to changes in the level of phenylalanine intake. Menkes (38) suggested that the reversible signs (such as eczema, hair pigment, muscular rigidity, hyperactivity, irritability, EEG abnormalities, and seizures) are associated with reversible competitive enzymatic inhibitions effected by the excessive amounts of phenylalanine and related compounds; whereas the irreversible signs (such as low IQ) result from structural abnormalities of the central nervous system (demyelination, spongy degeneration, gliosis) connected with alterations of proteins and lipids in the white matter.

Measurements of $1 \mathrm{Q}$ have been used to follow intellectual development on a low phenylalanine diet $(17,21,31)$ to determine when the special diet may be discontinued $(2,23,25,47)$, and to estimate extent of permanent brain damage (29); but such measures are relatively insensitive to any reversible effects of dietary changes in the older child with PKU.

The present investigation was designed to explore the use of tests tapping these reversible aspects of behavior and performance and to find out whether these data can be correlated with concurrent metabolic changes in different dietary phases $(5,46)$. In view of the exploratory nature of the study and the possibility of individual variability in response, we used a small number of subjects (Ss) but a large number of test sessions and trials per subject.

The use of institutionalized subjects with PKU has many obvious advantages for establishing a base rate of performance, for controlling diet, and for sampling blood and urine. The major 
disadvantage rests in the limited range of performance which can be studied in subjects with low IQ.

\section{SUBJECTS}

At the Faribault State Hospital there were 18 patients with PKU between the ages of 6 and 16. Only four were able to feed themselves, and thus able to reach for the candy reward essential for the test. These four subjects had classic PKU diagnosed on the basis of high serum phenylalanine (over $25 \mathrm{mg} / 100 \mathrm{ml}$ ) on regular diet and severe mental retardation (IQ under 40).

Subject I was a 7-year-old boy with dark brown hair, hazel eyes, an IQ of 35 , a serum phenylalanine level of $30-34 \mathrm{mg} / 100 \mathrm{ml}$, and one unaffected sib.

Subject II was a 15-year-old boy with light blonde hair, blue eyes, an IQ of 20 , a serum phenylalanine level of $28-35 \mathrm{mg} / 100$ $\mathrm{ml}$, and two sibs, both with PKU.

Subject III was a 12-year-old boy with brown-blonde hair, blue eyes, an IQ of 39 , a serum phenylalanine level of $20 \mathrm{mg} / 100 \mathrm{ml}$, and one unaffected half-sister.

Subject IV was a 15-year-old girl with light blonde hair, blue eyes, an IQ of 12, serum phenylalanine levels between 25 and 28 $\mathrm{mg} / 100 \mathrm{ml}$, one sib with PKU, and two unaffected sibs.

\section{DIET CHANGES}

Three types of diet were used in this investigation. (1) The general institutional diet is designated here as the regular diet. (2) A low phenylalanine diet ( $L O$ diet) (18) consisted of Lofenalac formula (casein hydrolysate), adjusted for use in adolescents to a caloric content of $45 \mathrm{cal} /$ ounce, with added fruits, juices, cereals, vegetables, small quantities of milk, toast, and jelly as sources of natural intact protein. This $L o$ diet was designed in such a way that the daily phenylalanine intake of 3,000-3,500 $\mathrm{mg}$ (in the regular diet) was reduced to $400-500 \mathrm{mg} / 24 \mathrm{hr}$, in order to lower the serum phenylalanine from $30-40 \mathrm{mg} / 100 \mathrm{ml}$ to a level between 4 and $8 \mathrm{mg} / 100 \mathrm{ml}$. (3) The third diet (designated Lo-plus) consisted of a $L o$ diet with added crystalline L-phenylalanine powder sufficient to bring the total phenylalanine intake close to that on the regular diet. This was done to eliminate nutritional differences (other than phenylalanine intake) between the Lo and regular diets, and to minimize the subjects' adjustment problems in a transition between diets.

About $80 \%$ of the total nitrogen content of the Lo diet is supplied by the casein-hydrolysate which contains all essential aminoacids except for traces of phenylalanine $(0.08 \%)$. Ten per cent of the nitrogen is offered in the form of natural intact protein to safeguard growth and development. Although the Lo diet contains $30-40 \%$ less protein nitrogen than the regular diet, a protein supply of $1.7 \mathrm{~g} / \mathrm{kg}$ in $S I$ (7-year old), $1.4 \mathrm{~g} / \mathrm{kg}$ in $S I I I$ (12-year old), and $1.0 \mathrm{gm} / \mathrm{kg}$ in $S$ 's $I I$ and $I V$ (15-year old), was sufficient to assure a positive nitrogen balance and weight gain.

The added L-phenylalanine was administered by subdividing the daily amount into three doses given in orange juice. For $S I$ we started with a dose of $120 \mathrm{mg} / \mathrm{kg} / 24 \mathrm{hr}$. The serum level rose to $34.5 \mathrm{mg} / 100 \mathrm{ml}$ on the $3 \mathrm{rd}$ day and to $61 \mathrm{mg} / 100 \mathrm{ml}$ on the $10 \mathrm{th}$ day. At the latter level the boy was perspiring, pale, listless, unsteady, and nauseated to the point of emesis. The amount of added phenylalanine was reduced immediately to $60 \mathrm{mg} / \mathrm{kg}$, which was sufficient to sustain a serum level of $30-38.5 \mathrm{mg} / 100 \mathrm{ml}$ without any obvious side effects. Thereafter, we used doses of $50-60 \mathrm{mg} / \mathrm{kg} / 24 \mathrm{hr}$, and these were adequate to maintain serum phenylalanine levels of $29-38 \mathrm{mg} / 100 \mathrm{ml}$ in $S^{\prime} s I, I I$, and $I V$ without side effects. In $S$ III, however, a dose of $62 \mathrm{mg} / \mathrm{kg} / 24 \mathrm{hr}$ resulted in a serum level of only $19.75-21 \mathrm{mg} / 100 \mathrm{ml}$.

The crucial point of the experiments in this paper consists in the addition or subtraction of crystalline phenylalanine to and from the $L o$ diet. Since this increase or decrease represents only $1.9-3.2 \%$ of the total nitrogen intake, these changes in nitrogen have to be considered as insignificant. Any changes in behavior or in test performance between the Lo and Lo-plus diet periods have to be attributed to the direct or indirect effects of various phenylalanine concentrations and resulting shifts in the distribution of amino acids.

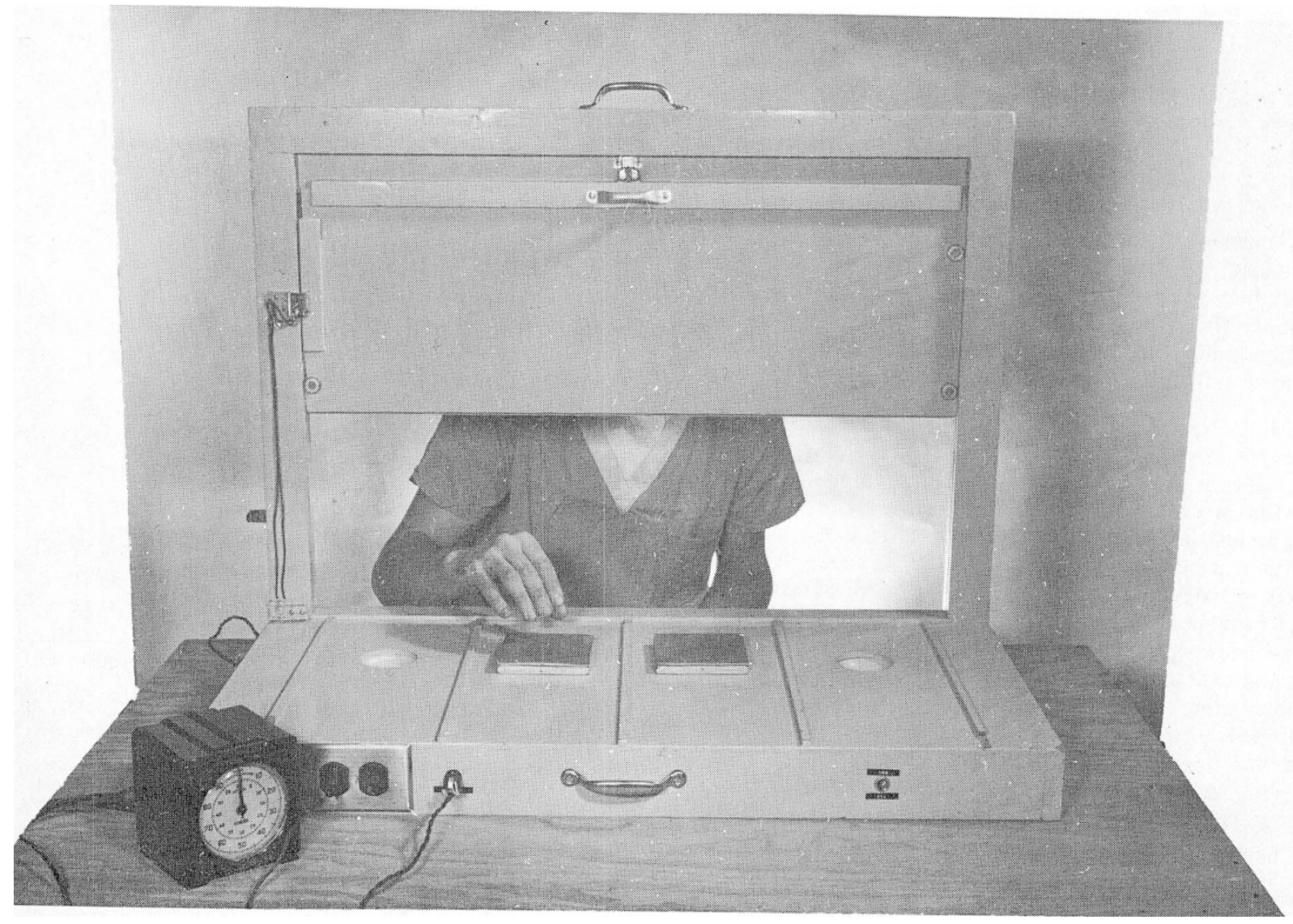

Fig. 1. Psychological test apparatus, viewed from the experimenter's side. 


\section{BEHAVIORAL STUDIES}

A position discrimination and reversal task was selected for two reasons: (1) House and Zeaman (27) found this type of problem to be the easiest for retarded subjects to master; (2) a task with which the subjects were unfamiliar would reduce the effect of established patterns of behavior which might be unresponsive to changes in the biochemical state.

This type of problem requires the subject to discriminate between two stimuli on the basis of their position (right or left). Subjects are rewarded for correct choices. After a predetermined number of consecutive correct choices, the rewarded position is reversed.

A modified Wisconsin General Test Apparatus was used, consisting of a horizontal panel (34 by 16 inches) and a vertical section ( 34 by 25 inches) which could be separated for easy transportation (Fig. 1). Four wells (2.5 inches in diameter) were spaced 4.5 inches apart on the horizontal panel, 4.5 inches from the edge nearest the subject. The vertical section had a movable panel which could be raised 9 inches, revealing the stimuli. The experimenter's (E's) face was screened from the $S$ at all times.

The stimuli were two green colored blocks ( 4 by 4 by 0.5 inch) placed over the two center wells, with the outer two wells remaining uncovered. A Standard clock calibrated to $1 / 100 \mathrm{sec}$ was used to measure the time of response from the time the door was raised until the subject pushed one of the blocks, releasing a magnetic swtich imbedded in the horizontal panel. This time interval is designated here as the "response latency."

In the first session the $\mathrm{S}$ was shown the two center wells, one of which contained a miniature marshmallow. On the second trial the well containing the reward was covered by a block, and the subject was encouraged to push the block and retrieve the candy. On subsequent trials both wells were covered. A reward was placed in the same well until the subject made 10 consecutive correct responses, at which time the reward was shifted to the other well. Each testing session consisted of 60 trials.

Three of the subjects were not allowed access to their reward unless they chose the correct position. Subject IV was unusually powerful, and apparently resented not receiving a reward for each trial. If denied access to the candy, she would push the vertical panel until it threatened to buckle and the whole apparatus was in danger of being pushed off the table. In order to spare the apparatus and the experimenter as well, she was rewarded for each response. The findings in other studies have suggested that the rate of learning in position discrimination is not affected by allowing correction (26).

Each subject was tested once a week during the course of the dietary changes. The testing sessions required between 13 and 35 min, depending on the subject. The first testing session started 1.5 $\mathrm{hr}$ after lunch. It was a continuing source of amazement to watch 50-60 marshmallows being consumed in such a short period with what seemed unflagging enthusiasm.

\section{TEST RESULTS}

The subjects mastered the task in the first two or three sessions and, subsequently, error scores remained stable in the different diet phases. The test probably was so simple and so well learned that the error scores were not affected by dietary change.

Changes in performance response latency were observed, however, and provide the primary data for the present report. The median response latency (of 60 trials) and the $95 \%$ confidence limits were calculated for each session. From the data we could not determine whether the increases in response latency were associated with slower perception time, variability in attention, or increased time required to carry out a response.

On the first test session after the change to a Lo-plus diet, the response latencies for $S I$ increased significantly, and a week later (when his serum phenylalanine level was very high) the response latencies increased further to a marked degree (Fig. 2). Subsequently, his response latencies decreased to the level observed on the Lo diet and remained stable throughout the rest of the testing.

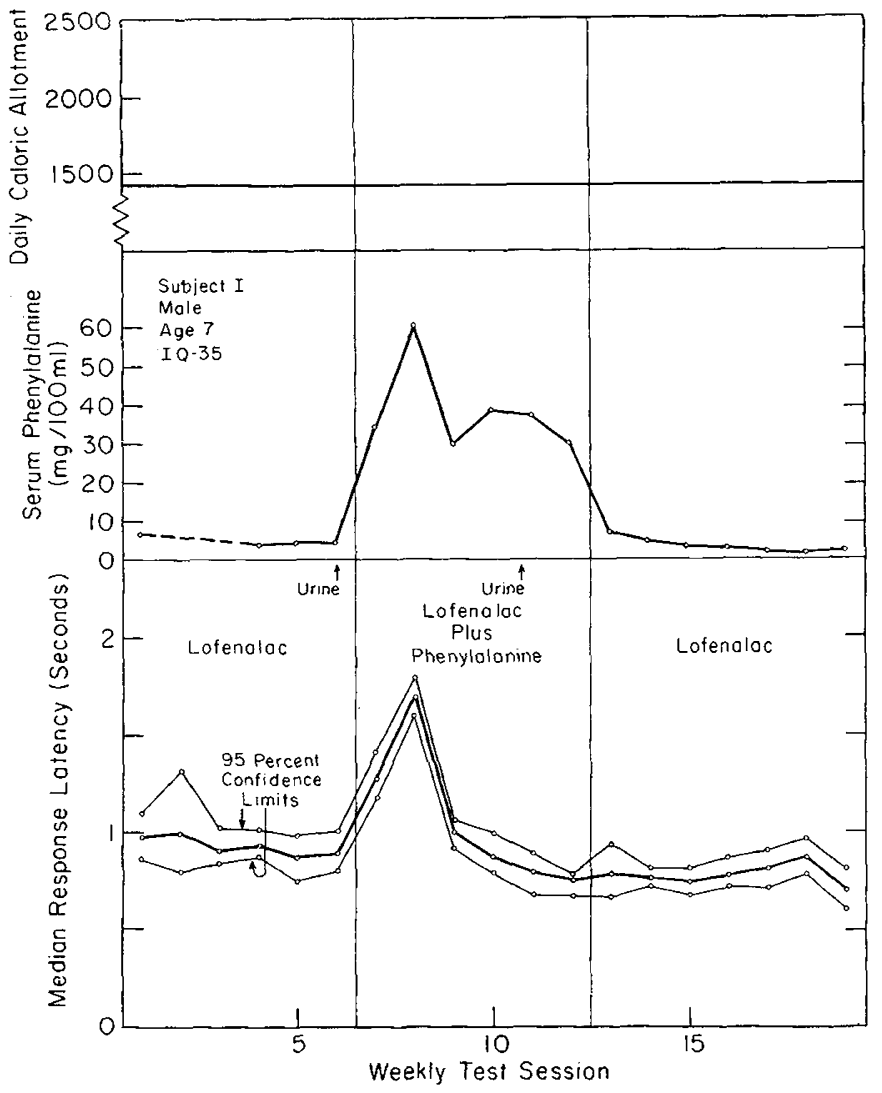

Fig. 2. Daily caloric allotment, serum phenylalanine level, and median response latency (with $95 \%$ confidence limits) for subject I at each weekly test session.

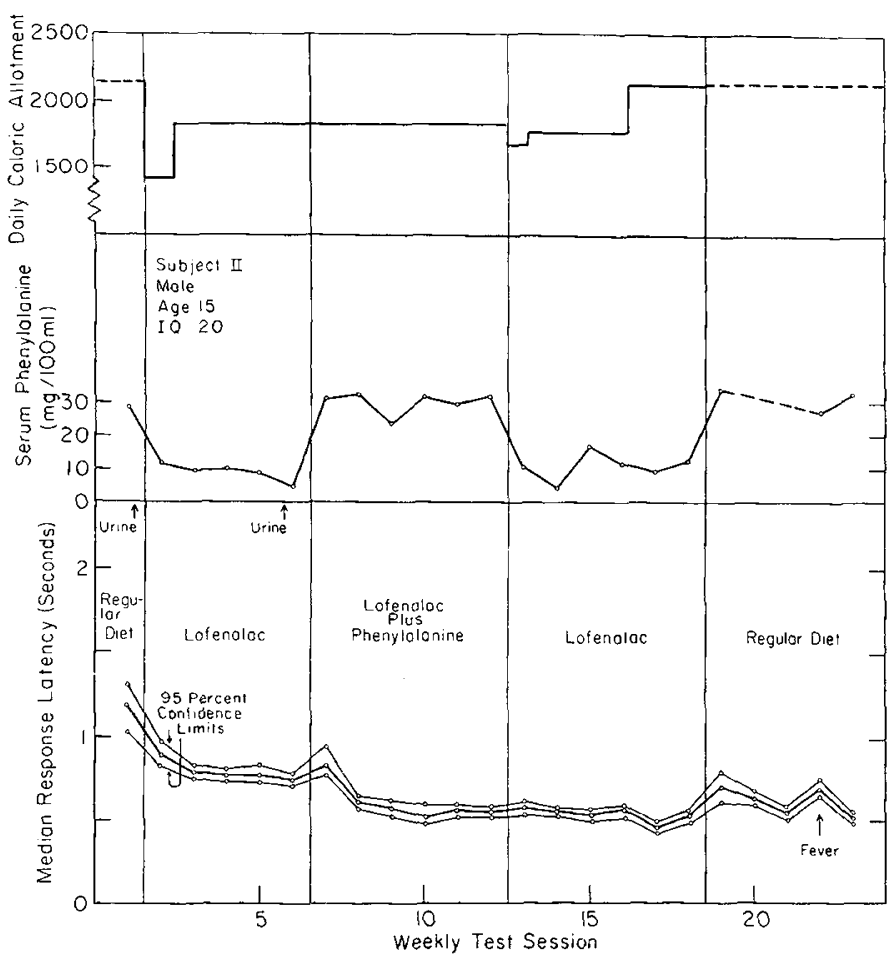

Fig. 3. Daily caloric allotment, serum phenylalanine level, and median response latency (with 95\% confidence limits) for subject II at each weekly test session.

In $S$ II's performance (Fig. 3) there was a decline in response latencies over the first three sessions (possibly the combined effect of the diet change and the subject's increasing familiarity with the task), followed by a plateau until the Lo-plus diet was introduced, 
at which point there was an increase in response latency lasting for only one test session. Subsequently, response latencies were lower than ever before, remaining stable for the next 11 weeks on the Lo-plus and Lo diets. The first week of the regular diet his response latencies increased and thereafter fell. His response latencies rose again in the 4 th week of the regular diet, but it was learned later that he had been ill on the day of testing with a temperature of $102^{\circ} \mathrm{F}$. A week later $S I I$ broke his arm, and the series was terminated.

$S$ III showed a different response to diet change as compared with $S I I$ (Fig. 4). The fall in response latency after the transition from a regular to a $L o$ diet occurred more gradually, over a period of about 4 weeks. After the addition of extra phenylalanine to the diet, the response latencies increased gradually, never to return to the low levels obtained under the $L o$ diet.

$S I V$ 's response latencies declined markedly over the first three sessions (presumably representing a learning curve). The latencies were elevated for two test sessions during a febrile illness. While on the $L o$ diet her performance was consistent from test to test, with relatively small variability within each test session. (It should be noted that the response latency scale in Figure 5 is reduced from that for the other subjects.) During the Lo-plus and the following

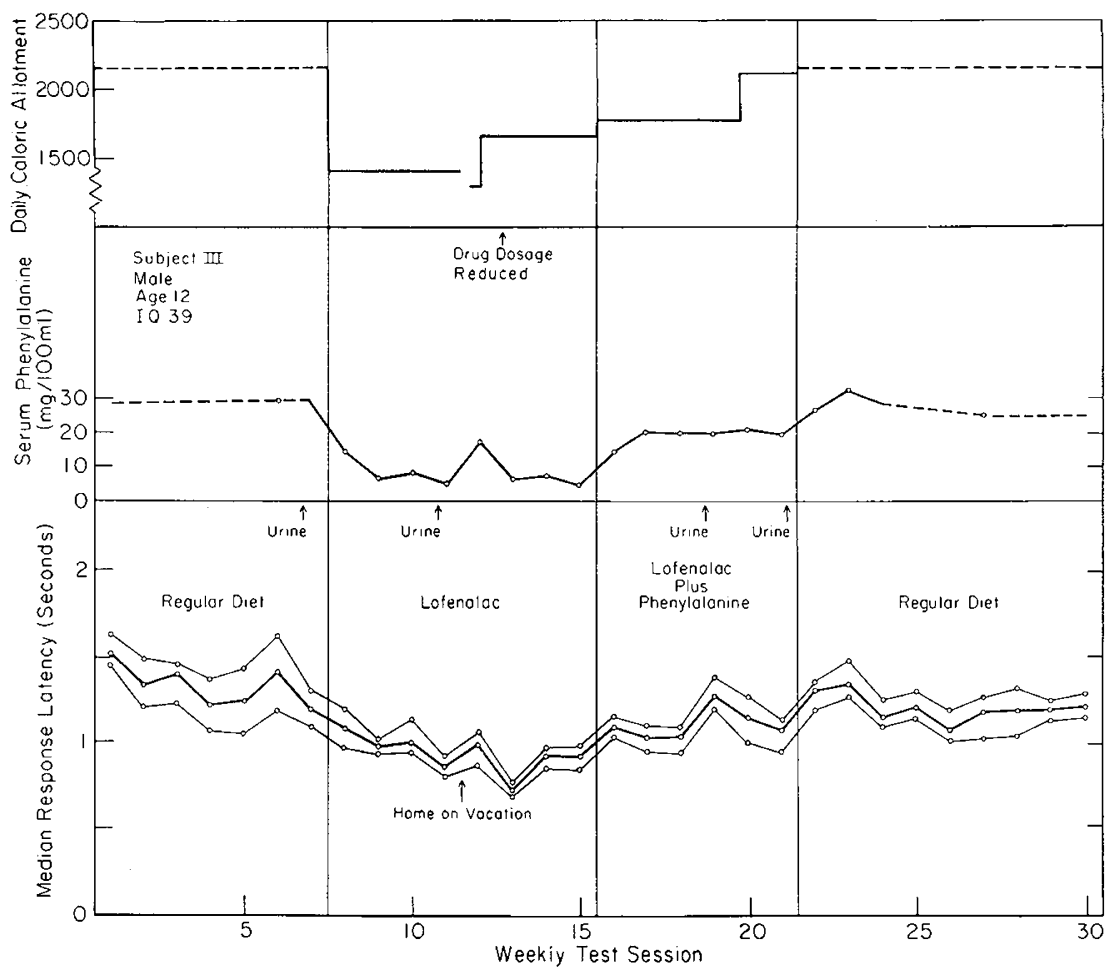

Fig. 4. Daily caloric allotment, serum phenylalanine level, and median response latency (with $95 \%$ confidence limits) for subject III at each weekly test session.

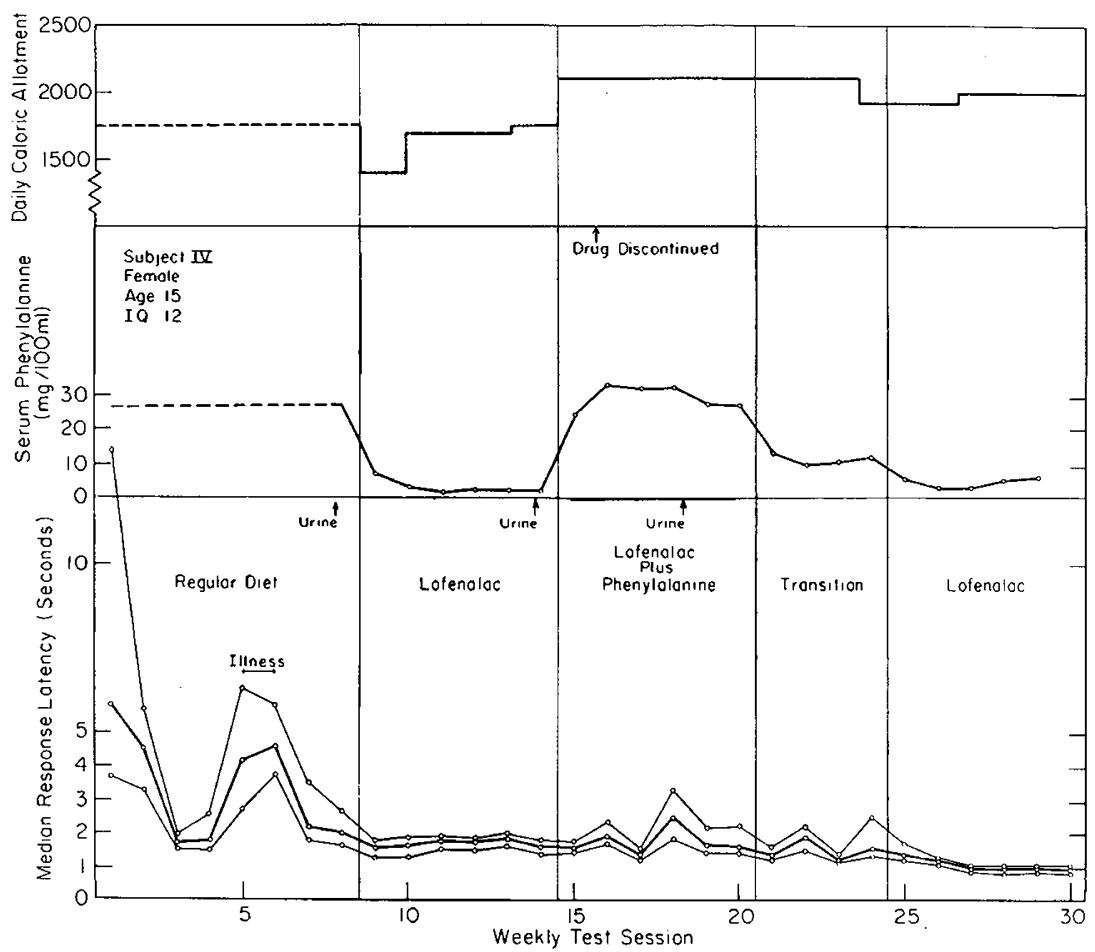

Fig. 5. Daily caloric allotment, serum phenylalanine level, and median response latency (with $95 \%$ confidence limits) for $s u b j e c t ~ I V$ at each weekly test session. 
transitional diet phases, however, her performance was much more variable, with some higher median values and with wider $95 \%$ confidence limits. At those test sessions when her response latencies were longer she appeared to be extremely hyperactive and unable to attend to the task. In the final $L o$ diet phase her response latencies were stable and very short.

\section{POSSIBLE EFFECTS OF DIET (ASIDE FROM PHENYLALANINE INTAKE)}

Some attention must be given to the possibility that changes in diet might affect the reinforcing properties of the candy used as a reward. A feeling of hunger often accompanies a Lo diet (even when the caloric intake is the same as that of a regular diet). Any such feeding could be assumed similar for the Lo and Lo-plus diet phases, but it might be less on a regular diet. On the Lo and LOplus diets the caloric intake was fairly evenly distributed over the three meals, whereas, on the regular diet the large meal was served at noon.

As a test for a general effect of diet phase the response latencies for the first 20 trials were compared with the last 20 trials within each 60 -trial session for each subject. No consistent differences were found. Thus, within each diet condition there was no evidence of satiation or fatigue within test sessions.

The caloric intake for each subject is shown in the top portion of Figures 2-5. The major changes in response latency (at least comparing the Lo and Lo-plus diets) appear not to be explained by changes in caloric intake.

\section{POSSIBLE EFFECTS OF MEDICATION}

All subjects had been on phenothiazine medication for some time prior to the onset of the present study. Investigations on the effects of phenothiazine have shown a reduction in motor speed and vigilance (33).

The dosages for $S$ ' $S I$ and $I I$ remained constant throughout the entire period of this study ( $15 \mathrm{mg}$ Compazine $/ 24 \mathrm{hr}$ for $S I$ and 150 $\mathrm{mg}$ Mellaril $/ 24 \mathrm{hr}$ for $S I I)$. For $S I I I$ the dosage of Mellaril was reduced from $75 \mathrm{mg}$ to $25 \mathrm{mg} / 24 \mathrm{hr}$ after the 6th week of the $L O$ diet because of noticeable improvement in behavior. His performance during the following 2 weeks of the Lo diet appeared unchanged, however. His response latencies did not increase until after he was placed on the Lo-plus diet.

While on regular diet $S I V$ was excitable, hyperactive, noisy, and unmanageable, even though she was maintained on $150 \mathrm{mg}$ Mellaril $/ 24 \mathrm{hr}$. On the Lo diet she became friendly, smiling, and responsive; this improvement was so impressive that the medication was discontinued for the remainder of the study. During the subsequent Lo-plus diet phase she gradually became irritable again and by the 21 st session had become hyperactive and noisy, with an erratic test performance. Her response latencies during the second Lo diet phase appeared to be both lower and less variable than during the first $L O$ diet period, perhaps as a result of the absence of the tranquilizing drug.

We concluded that the major changes in response latency could not be explained by changes in mediation.

\section{BIOCHEMICAL STUDIES}

The quantitative variations of the following biochemical parameters were studied: serum phenylalanine, serum tyrosine, and the urinary metabolites of phenylalanine, tyrosine, and tryptophan.

\section{BIOCHEMICAL METHODS}

Blood samples were taken every week on the day before psychological testing (at times indicated in Figs. 2-5) for phenylalanine and tyrosine determinations according to the method of Udenfriend and Cooper $(49,50)$.

One 24-hr urine sample was collected (on ice) during each dietary phase and stored in deep freeze, for determination of the following metabolites: phenylpyruvic acid (PPA) according to the method of Kropp and Lang (34), o-hydroxyphenylacetic acid (o-HPAA) by paper chromatography (13), p-hydroxyphenylpyruvic acid ( $p$-HPPA) according to the method of Wegner (53), total ketoacids according to the method of Armstrong and Low (8), indole-3-acetate (I-3-AA) (54), and 5-hydroxyindole acetic acid (5-HIAA) (51). Seven metabolites of tryptophan of the formylkynurenine pathway (kynurenine, acetylkynurenine, 3hydroxykynurenine, 3-hydroxyanthranilic acid, anthranilic acid, anthranilic glucuronide, and $o$-aminohippuric acid) were determined by elution chromatography (39).

\section{BIOCHEMICAL RESULTS}

Table 1 shows the means of all phenylalanine and tyrosine values (from 6 to 10 blood samples within each diet phase for each subject). The variations in the serum phenylalanine levels obviously reflect the variations in phenylalanine intake during the three diet phases. That an oral L-phenylalanine dose of $60 \mathrm{mg} / \mathrm{kg} / 24 \mathrm{hr}$ resulted in different blood levels in the four subjects (during the Lo-plus phase) would suggest individual variations in phenylalanine absorption and phenylalanine hydroxylase or transaminase activity.

The mean values for serum tyrosine during regular diet were in the low normal range for $S$ ' $S I$ and $I I$ and in the normal range for $S$ 's $I I I$ and $I V$ (normal $0.81-1.45 \mathrm{mg} / 100 \mathrm{ml}$; mean $1.03 \mathrm{mg}$ ) (2). The values decreased slightly in $S$ ' $S I$ and $I I$ but significantly in $S$ 's $I I I$ and $I V$ on the $L O$ diet, and remained unchanged on addition of oral L-phenylalanine. Lower tyrosine values for PKU children while on Lo diet have been attributed to insufficient tyrosine supply from the Lofenalac diet $(1,3,16)$.

The data in Table 2 show that the urinary excretion of $o$-HPAA, PPA, total $\alpha$-keto acids (with the exception of $p$-HPAA), and the

Table 1. Mean serum phenylalanine and tyrosine levels for each subject within each diet phase

\begin{tabular}{|c|c|c|c|c|c|c|c|c|c|c|c|c|}
\hline \multirow{2}{*}{ Subject } & \multicolumn{6}{|c|}{ Serum phenylalanine, $\mathrm{mg} / 100 \mathrm{ml}$} & \multicolumn{6}{|c|}{ Serum tyrosine, $\mathrm{mg} / 100 \mathrm{ml}$} \\
\hline & \multicolumn{2}{|c|}{ Regular } & \multicolumn{2}{|c|}{ Lo } & \multicolumn{2}{|c|}{ Lo-plus } & \multicolumn{2}{|c|}{ Regular } & \multicolumn{2}{|c|}{ Lo } & \multicolumn{2}{|c|}{ Lo-plus } \\
\hline$I$ & \multicolumn{2}{|c|}{$(33.4)^{2}$} & 4.0 & 0.6 & 38.5 & 4.8 & \multicolumn{2}{|c|}{$(0.80)^{2}$} & 0.78 & 0.08 & 0.90 & 0.09 \\
\hline II & 30.0 & 2.0 & 10.0 & 1.0 & 29.8 & 1.5 & 0.94 & 0.16 & 0.71 & 0.05 & 0.86 & 0.08 \\
\hline All tests & 29.0 & 0.8 & 6.3 & 0.6 & 29.3 & 1.9 & 1.14 & 0.06 & 0.76 & 0.03 & 0.84 & 0.04 \\
\hline
\end{tabular}

${ }^{1}$ For explanation of regular, Lo, and Lo-plus diets, see the text.

${ }^{2}$ Mean of two values before study.

${ }^{3}$ Single value before study. 
fraction of unidentified $\alpha$-keto acids (estimated as the difference between total $\alpha$-keto acids and the sum of PPA and $p$-HPPA) fell and rose parallel to the serum phenylalanine level. The values of all these acids were essentially zero on the $L o$ diet for all four subjects.

The observation in the preceding paragraph has been interpreted by many investigators $(9,11,17,28-30)$ as a "normalization of the deranged metabolism in PKU." Addition of crystalline $\mathrm{L}$ phenylalanine to the $L o$ diet reversed this effect with reappearance of all the abnormal metabolites. However, it should be noted that the excretion of PPA and the other keto acids on the Lo-plus diet remained below the excretion on the regular diet by $50-75 \%$ in $S$ 's $I I$ and $I I I$. This finding is explained by the fundamental difference between regular diet and the Lofenalac diet, which is a hydrolysate of free amino acids (4). In $S I V$, however, the excretion levels on regular diet were similar to those on the Lo-plus diet, an indication of individual metabolic variability.

The excretion of $p$-HPPA seemed to follow a different pattern (Table 2). It frequently is not altered by a $L o$ diet because, in view of the block in conversion of phenylalanine to tyrosine, it is derived mainly from dietary tyrosine (17). Essentially, no change was shown by $S$ ' $I$ and $I I$ in all diet phases. The changes in $S$ 's $I I I$ and $I V$ are somewhat larger and occurred in opposite directions in the $L o$ diet phase, an increase from 1.0 to $1.9 \mathrm{mg} / 24 \mathrm{hr} / \mathrm{kg}$ in $S I I I$, but a decrease from 1.2 to $0.4 \mathrm{mg} / 24 \mathrm{hr} / \mathrm{kg}$ in $S I V$. This might reflect tyrosine intake on that particular day or metabolic variation of the subject.

The excretion of the metabolites of the kynurenine and of the indoleacetic pathways was similar (within I SD) in all three diet phases for $S$ 's $I$ and $I V$, whereas $S$ 's $I I$ and $I I I$ showed an elevation of these metabolites on regular diet (Table 2). For the kynurenine metabolites, this elevation did not exceed 2 SD over normal values (39). The excretion of I-3-AA was almost 3 SD over normal values on regular diet for $S$ 's $I I$ and $I I I$. It decreased to normal values on $L o$ diet and remained unchanged on addition of oral
L-phenylalanine. In $S I V$ the excretion of 1-3-AA was normal on regular diet and remained so for the $L O$ and Lo-plus diet. In $S I$ excretion was normal both in the Lo and in the Lo-plus diet periods.

An elevation of indoles in untreated PKU patients is a frequent, although not constant, finding (10), explained by malabsorption of tryptophan in the gut (57), prolonged enzymatic action of intestinal bacteria, and the inability of the PKU liver to clear the indoles and indican from the blood (15). Under a Lo diet all of these abnormalities are reversed.

In contrast to such individual variability in metabolic responses both for the oxidative and indole-pyruvic pathways of tryptophan (4), the response to dietary changes was similar for all four subjects in the excretion of 5-HIAA (the urinary end product of the serotonin pathway): 5-HIAA was low on regular diet, increased somewhat on the Lo diet, and fell again to low levels on addition of oral L-phenylalanine. This pattern has been described by other investigators $(12,42)$.

The changes in the excretion of metabolites which accompany the changes in phenylalanine level in the three diet phases reflect clearly the alterations in the metabolic derangement that exist not only in the blood and tissue cells of the body $(20,35,36)$, but must also involve the brain of PKU patients (32). It is obvious that metabolic changes within the central nervous system might be too subtle to become detectable directly by the comparatively gross methods used in the present investigation. However, numerous and extensive investigations during the past 20 years indicated that it is most likely that the brain metabolism in PKU is severely distorted either by an excess of metabolites such as PPA, $o$-HPPA, different indoles, $O$-tyramine, phenylethylamine $(40,41,48)$, or deficiencies of other metabolites, such as tyrosine, glutamic acid, epinephrine, norepinephrine, and serotonin $(14,28,30,37,38,43)$, in the central nervous system.

In their discussion of brain metabolism in PKU, Knox and Hsia (30) stated that "the chemical milieu is so distorted from its

Table 2. Serum and urinary levels of selected substances for each subject $(I-I V)$ within each diet phase ${ }^{1}$

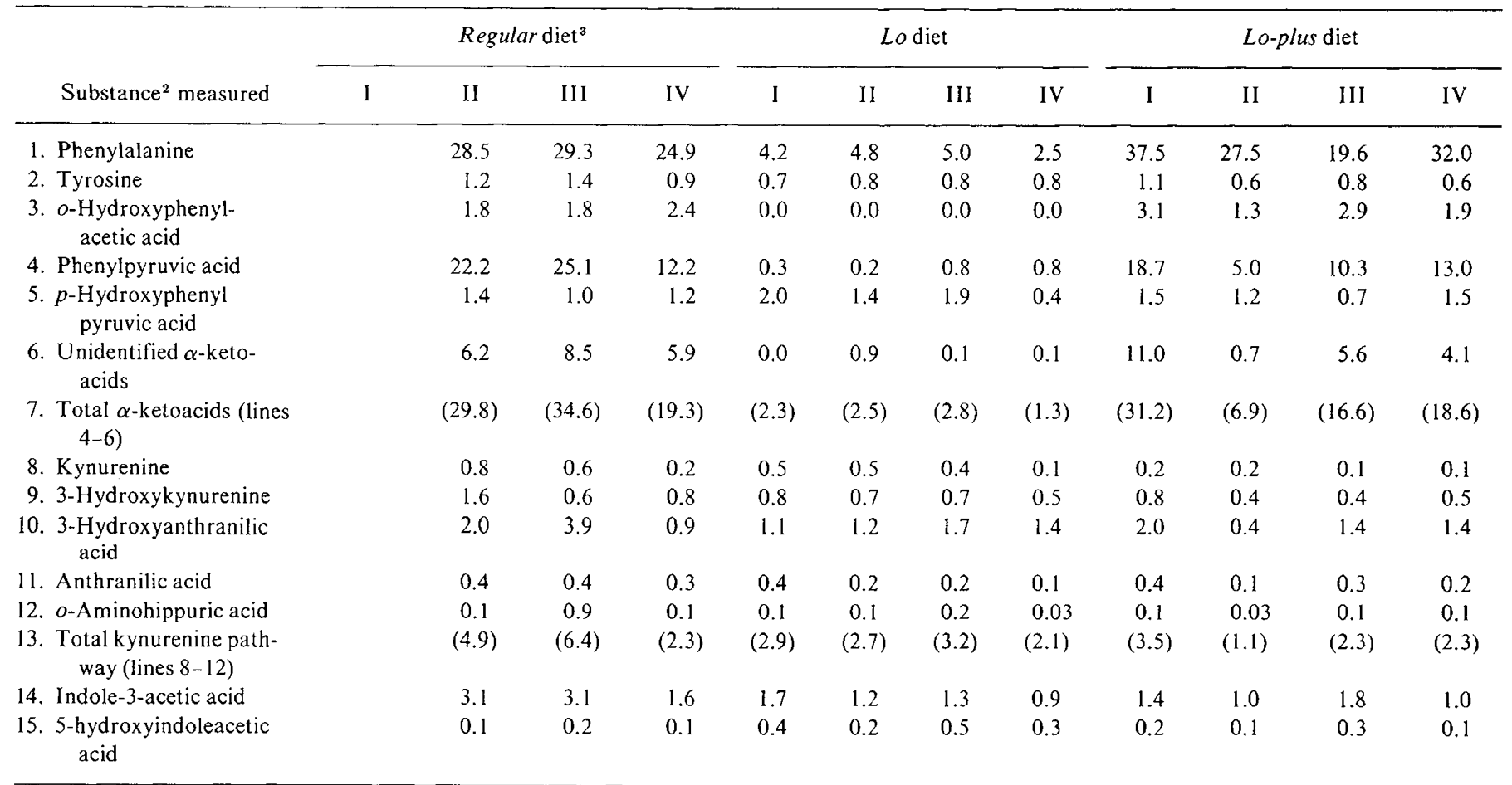

${ }^{1}$ For explanation of regular, Lo, and Lo-plus diet, see the text.

${ }^{2}$ Lines 1-2 show the serum level for each subject closest to the time of urine collection, expressed as mg/100 ml. Lines 3-7 are from urine, expressed as

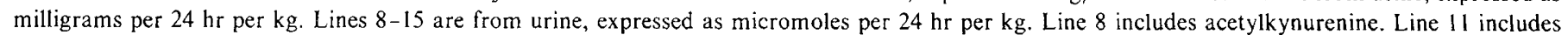
anthranilic acid glucuronide. The body weights of the four Subjects, respectively, were $23 \mathrm{~kg}, 56 \mathrm{~kg}, 30.5 \mathrm{~kg}$, and $43 \mathrm{~kg}$.

${ }^{3}$ Urinary values were not available for subject $I$ on regular diet. 
normal homeostatic balance, that normal function of cells could not be maintained." Menkes (38) assumed that "in the presence of the unusually high tissue concentrations of intermediary metabolites, a large number of enzymatic systems operate at less than optimum rate" both in the extracerebral tissues and in the cells of the central nervous system. The decreased cerebral arteriovenous oxygen difference (24) and the abnormal EEG in PKU are indications for a cerebral dysfunction.

\section{RELATIONSHIP BETWEEN BEHAVIORAL AND BIOCHEMICAL DATA}

In an attempt to correlate observed psychological and metabolic data, it is reasonable to test the hypothesis that psychological test performance depends on the state of cerebral metabolism and function and may serve as an indication for it. We might expect poor test performance as an indication of cerebral dysfunction in diet phases with a high serum phenylalanine level, whereas improvement of cerebral function and test performance should be noted in a $L O$ diet period.

One way to test this hypothesis is through visual inspection of Figures 2-5, comparing the median response latencies (and the $95 \%$ confidence limits) with the serum phenylalanine levels. A second approach is to calculate the correlation coefficient between the phenylalanine levels and the response latencies, both with respect to the median response time and to the variability in response time within each session (Table 3 ).

$S I I I$ (Fig. 4) showed a parallelism between performance and diet phases, with increased response latencies (slower responses) during high phenylalanine diet phases and low response latencies (faster responses) while on a low phenylalanine diet. The correlation between median response latency and phenylalanine level is highly significant, but the correlation with variation in response time (adjusted for median) is not significantly different from zero.

$S I V$ (Fig. 5) showed a partly similar and partly different reaction. On the Lo diet her response latencies were low, i.e., the responses to the task were faster (like $S I I I)$. This performance was very stable and contrasted to the erratic performance during the high phenylalanine phases. During latter periods the response latencies were increased during some sessions but not in others. In addition, she was extremely excited, irritable, hyperactive, and unable to attend to the task. The calculations in Table 3 show a significant association with phenylalanine level, both for median response latency and for response variability.

Subjects $I$ and $I I$ (Figs. 2 and 3) showed a reaction to the diet change that was entirely different. Response latencies increased upon elevation of the serum phenylalanine level, either by change to the Lo-plus (SI and $S I I$ ) or to regular diet $(S I I)$, and during a febrile illness $(S I I)$. But these reactions were only transient, and response latencies returned to their previous level after 2 weeks in $S I$ and after 1 week in $S I I$. In $S I$ there was a significant correlation between phenylalanine level and median response latency, but this depended entirely upon the two sessions with highest levels (Table 3). The transient effect in these two subjects may have resulted directly from the changes in serum phenylalanine levels, or might represent nonspecific responses to a relatively abrupt alteration of this single dietary component. Nevertheless, it is clear that $S$ 'S $I$ and $I I$ showed an adaptation to the high phenylalanine intake that was not seen in $S$ 's $I I I$ and $I V$.

This variability on the psychological level in response to dietary changes is noteworthy. Similarly, a variability was observed in our subjects in metabolic responses to phenylalanine loading, especially in the excretion of tryptophan metabolites.

It is of interest that Frankenburg et al. (22) observed the same features of adaptation and variability in their study of seven phenylketonuric children placed on the equivalent of our Lo-plus diet and followed with daily and weekly behavioral assessment scales. Two children showed essentially no behavioral change. Four showed a marked increase in irritability and lethargy, but this response was transient and their behavior improved after about 10 days while still on the elevated phenylalanine intake. One child's behavior (the most retarded) showed a continuing deleterious effect and improved only when serum phenylalanine levels were reduced.

There are two possible explanations for the adaptation noted in our $S$ ' $I$ and $I I$ and in four PKU subjects studied by Frankenburg et al (22). (1) Biochemical mechanisms outside of the brain might have been activated. This could reduce the level of certain toxic metabolites or counteract their effect. Our metabolic data, based on a single urinary collection during each diet period, were not extensive enough to test such an hypothesis. (2) After an initial shock, the central nervous system might have developed an adaptive response which minimized the potentially deleterious effect of a high concentration of phenylalanine or its metabolites.

The individual variability also may have several different explanations. There is a strong suggestion that those with more brain damage are less able to tolerate elevated phenylalanine levels. The EEG's of $S$ 's $I$ and $I I$, who were able to adapt, were normal (in $S I$ ) or borderline (in $S I I$ ), whereas the EEG's of $S$ 's $I I I$ and $I V$ showed a severe dysrhythmia in the form of a spiking focus (in $S I I I$ ) or spike-slow wave paroxysms (in $S I V$ ). In the Frankenburg series the most retarded child was most affected by the supplemental phenylalanine. A somewhat similar conclusion may be reached from Saugstad's finding (45) that untreated phenylketonuria patients whose prenatal course was associated with more obstetric problems tended to have a lower IQ. Finally, there remains the possibility of genetic variations affecting the phenylalanine hydroxylase system itself or the adaptive mechanisms mentioned in the preceding paragraph.

\section{SUMMARY}

This study was initiated to test a research design involving the simultaneous analysis of biochemical and behavioral parameters in

Table 3. Correlation between serum phenylalanine level and response latency

\begin{tabular}{|c|c|c|c|c|c|c|}
\hline \multirow[b]{2}{*}{ Subject } & \multirow{2}{*}{$\begin{array}{l}\text { Test sessions } \\
\text { included }\end{array}$} & \multirow{2}{*}{$\begin{array}{c}\text { No. of test } \\
\text { sessions }\end{array}$} & \multicolumn{2}{|c|}{$\begin{array}{c}\text { Correlation between phenylalanine } \\
\text { level and median response } \\
\text { latency }\end{array}$} & \multicolumn{2}{|c|}{$\begin{array}{c}\text { Correlation between phenylalanine } \\
\text { level and response } \\
\text { variability }{ }^{1}\end{array}$} \\
\hline & & & $r$ & $P(r=0)$ & $r$ & $P(r=0)$ \\
\hline$I$ & 4-19 & 16 & $0.71^{2}$ & $<0.01$ & 0.10 & N.S. \\
\hline$I I$ & $1-19,22-23$ & 21 & 0.03 & N.S. & 0.40 & N.S. \\
\hline$I I I$ & $6,8-24,27$ & 19 & 0.86 & $<0.001$ & $0.61^{3}$ & $<0.01$ \\
\hline$I V$ & $8-29$ & 22 & 0.47 & $<0.05$ & $0.55^{4}$ & $<0.01$ \\
\hline
\end{tabular}

${ }^{1}$ Variability was measured by the difference between the lower and upper bounds of the $95 \%$ confidence limits for the median response latency.

${ }^{2}$ If the two highest values (sessions 7 and 8 ) are excluded, $r=0.19$ (N.S.).

${ }^{3}$ If the $95 \%$ confidence band is divided by the median for each test session, $r=0.43$ (N.S.).

${ }^{4}$ If the $95 \%$ confidence band is divided by the median for each test session, $r=0.46(P<0.05)$. 
sufficient detail to permit the detection of individual variability. The basic strategy can be altered to include other tissues, such as granulocytes $(7)$, other biochemical parameters $(44,52)$, and other behavioral measures, such as the continuous performance test (6). The results presented here, together with those from other recent studies, demonstrate the feasibility and potential usefulness of such an approach for patient care and for basic research into the mechanisms whereby phenylketonuria affects behavior.

\section{REFERENCES AND NOTES}

1. Acosta, P.: Serum tyrosine levels of phenylketonuric children. Proceedings of International Symposium on Phenylketonuria and Allied Disorders, Discussion Session 7, p. 261, Tel-Aviv, June 15-22, (1969).

2. Altman, P. L., and Dittmer, D. S.: Biological Handbooks: Blood and Other Body Fluids (Federation of American Societies For Experimental Biology, Washington, D. C., 1961).

3. Anderson, J. A.: Serum tyrosine levels of phenylketonuric children on lowphenylalanine diet. Proceedings of International Symposium on Phenylketonuria and Allied Disorders, Discussion Session 2, p. 127, Discussion Session 7, p. 259, Tel-Aviv, June 15-22, (1969).

4. Anderson, J. A., Bruhl, H. H., Michael, A. F., and Doeden, D.: Tryptophan oxidation in phenylketonuria. Pediat. Res., $1: 372$ (1967).

5. Anderson, V. E., and Siegel, F.: Studies of behavior in genetically defined syndromes in man. In: S. G. Vandenberg: Progress in Human Genetics. Recent Reports on Genetic Syndromes, Twin Studies and Statistical Advances, p. 7 (Johns Hopkins Press, Baltimore, 1968).

6. Anderson, V. E., Siegel, F. S., Fisch, R. O., and Wirt, R. D.: Responses of phenylketonuric children on a continuous performance test. J. Abnorm. Psychol., 74: 358 (1969).

7. Andrews, T. M., McKeran, R. O., Watts, R. W. E., McPherson, K., and Lax, R.: A relationship between the granulocyte phenylalanine content and the degree of disability in phenylketonuria. Quart. J. Med., 168: 805 (1973).

8. Armstrong, M. D., and Low, N. L.: Phenylketonuria. VIII. Relation between age, serum phenylalanine level, and phenylpruvic acid excretion. Proc. Soc. Exp. Biol. Med., 94: 142 (1957).

9. Armstrong, M. D., Low, N. L., and Bosma, J. F.: Studies on phenylketonuria. IX. Further observations on the effect of phenylalanine-restricted diet on patients with phenylketonuria. Amer. J. Clin. Nutr., 5: 543 (1957).

10. Armstrong, M. D., and Robinson, K. S.: On the excretion of indole derivatives in phenylketonuria. Arch. Biochem. Biophys., 52: 287 (1954).

11. Armstrong, M. D., and Tyler, F. H.: Studies on phenylketonuria. I. Restricted phenylalanine intake in phenylketonuria. J. Clin. Invest., 34: 565 (1955).

12. Berendes, H., Anderson, J. A., Priggie, P., Ruttenberg, D., and Ziegler, M. R.: Phenylketonuria. Univ. Minn. Med. Bull., 29: 498 (1958).

13. Berry, H., Umbarger, B., and Sutherland, B.: Procedures for monitoring the low phenylalanine diet in treatment of phenylketonuria. J. Pediat., 67:609 (1965).

14. Bessman, S. P.: Some biochemical lessons to be learned from phenylketonuria. J. Pediat., 64: 828 (1964).

15. Bessman, S. P., and Tada, K.: Indicanuria in phenylketonuria. Metab. (Clin Exp.) 9: 377 (1960).

16. Bickel, H., Boscott, R. J., and Gerrard, J.: Observations on the biochemical error in phenylketonuria and its dietary control. In: H. Waelsch: Biochemistry of the Developing Nervous System, p. 417 (Academic Press, New York, 1955).

17. Bickel, H., and Grüter, W.: Management of phenylketonuria. In: F. L. Lyman: Phenylketonuria, p. 136 (Charles C Thomas, Publisher, Springfield, Ill., 1963).

18. Bruhl, H. H.: Dietary treatment in older PKU patients. Presented at a symposium on Nutrition and the Inherited Diseases of Man, Minneapolis, May 15, 1966

19. Bruhl, H. H., Arneson, J. F., and Bruhl, M. G.: Effect of a low phenylalanine diet on older phenylketonuria patients. (Long range controlled study.) Amer. J. Ment. Defic., 69: 225 (1964).

20. Efron, M. L., Kang, E. S., Visakorpi, J., and Fellers, F. X.: Effect of elevated plasma phenylalanine levels on other amino acids in phenylketonuric and normal subjects. J. Pediat., 74: 399 (1969).

21. Fisch, R. O., Torres, F., Gravem, H. J., Greenwood, C. S., and Anderson, J. A.: Twelve years of clinical experience with phenylketonuria. Neurology, 19: 659 (1969).

22. Frankenburg, W. K., Goldstein A., and Olson, C. O.: Behavioral consequences of increased phenylalanine intake of phenylketonuric children: A pilot study. Amer. J. Ment. Defic., 77: 525 (1973).

23. Fuller, R., and Shuman, J. L.: Treated phenylketonuria: Intelligence and blood phenylalanine levels. Amer. J. Ment. Defic., 75: 539 (1971).

24. Himwich, H. E., and Fazekas, J. F.: Cerebral arteriovenous oxygen difference. II. Mental deficiency. Arch. Neurol. Psychiat., 51: 73 (1944).

25. Horner, F. A., Streamer, C. W., Alejandrino, L. L., Reed, L. H., and Ibott, F.: Termination of dietary treatment of phenylketonuria. N. Engl. J. Med., 266: 79 (1962).

26. House, B. J., and Zeaman, D.: Visual discrimination learning in imbeciles. Amer. J. Ment. Defic., 63: 447 (1958).

27. House, B. J., and Zeaman, D.: Position discrimination and reversals in low grade retardates. J. Comp. Physiol. Psychol., 52: 564 (1959)

28. Jervis, G. A.: Pathogenesis of the mental defect. In: F. L. Lyman: Phenylketonuria, p. 101 (Charles C Thomas, Publisher, Springfield, Ill., 1963).
29. Knox, W. E.: Evaluation of the treatment of phenylketonuria with diets low in phenylalanine. Pediatrics, 26: 1 (1960).

30. Knox, W. E., and Hsia, D. Y.-Y.: Pathogenetic problems in phenylketonuria. Amer. J. Med., 22: 687 (1957).

31. Koch, R., Acosta, P., Fishler, K., Schaeffler, F., and Wohlers, A.: Clinical observations on phenylketonuria. Amer. J. Dis. Child., 113: 6 (1967).

32. Korey, S. R.: A possible mechanism in phenylpyruvic oligophrenia. Presented at the Twenty-third Ross Pediatric Research Conference, Winston-Salem, N. C. November 8, 1956.

33. Kornetsky, C., Vates, T. S., and Kessler, E. K.: A comparison of hypnotic and residual psychological effects of single doses of $\mathrm{CPZ}$ and secobarbital in man. J. Pharmacol. Exp. Ther., 127: 51 (1959).

34. Kropp, K., and Lang, K.: Eine colorimetrische Method zur quantitativen Bestimmung der Phenylbrenztraubensäure im Harn. Klin. Wochenschr., 33. 482 (1955).

35. Lines, D. R., and Waisman, H. A. Urinary amino acid excretion in phenylketonuric, hyperphenylalaninemic and normal patients. J. Pediat., 78: 474 (1971).

36. Linneweh, F., and Ehrlich, M.: Die Renalen und prärenalen Störungen des Aminosäuren-Stoffwechsels bei phenylalaninarmer Ernährung. Klin. Wochenschr., 38: 904 (1960).

37. McKean, C. U., and Peterson, N. A.: Glutamine in the phenylketonuric central nervous system. N. Engl. J. Med., 283: 1364 (1970).

38. Menkes, J. H.: Pathogenesis of mental retardation in phenylketonuria and other inborn errors of amino acid metabolism. Pediat. 39: 297 (1967).

39. Michael, A. F., Drummond, K. N., Doeden, D., Anderson, J. A., and Good, R. A.: Tryptophan metabolism in man. J. Clin. Invest., 43: 1730 (1964).

40. Mitoma, C., Posner, H. S., Bogdanski, D. F., and Udenfriend, S.: Biochemical and pharmacological studies on 0 -tyrosine and its meta and para analogues: A suggestion concerning phenylketonuria. J. Pharmacol. Exp. Ther., 120: 188 (1957)

41. Oates, J. A., Nirenberg, P. Z., Jepson, S. B., Sjoerdsma, A., and udenfriend, S.: Conversion of phenylalanine to phenethylamine in patients with phenylketonuria. Proc. Soc. Exp. Biol. Med., II2: 1078 (1963).

42. Pare, C. M. B., Sandler, M., and Stacey, R. S.: 5-Hydroxytryptamine deficiency in phenylketonuria. Lancet, $i$ : 551 (1957).

43. Perry, T. L., Hansen, S., Tischler, B., Bunting, R., and Diamond, S.: Glutamine depletion in phenylketonuria: A possible cause of the mental defect. N. Engl. J. Med., 282: 761 (1970).

44. Rampini, S., Volmin, J. A., Bosshard, H. R., Muller, M., and Curtius, H. C. Aromatic acids in urine of healthy infants, persistent hyperphenylalaninemia, and phenylketonuria, before and after phenylalanine load. Pediat. Res., 8: 704 (1974)

45. Saugstad, L. F.: The influence of obstetric complications on the clinical picture in phenylketonuria. Clin. Genet., 4: 115 (1973).

46. Siegel, F. S., Anderson, V. E., and Bruhl, H. H.: The effect of diet change on position discrimination and reversals in phenylketonuria. Univ. Minn. Med. Bull., 38: 217 (1967).

47. Solomons, G., Keleske, L., and Opitz, E.: Evaluation of the effects of terminating the diet in phenylketonuria. J. Pediat., 69: 596 (1966).

48. Udenfriend, S.: The primary enzymatic defect in phenylketonuria and how it may influence the central nervous system. In: J. A. Anderson and K. F. Swaiman: Phenylketonuria and Allied Metabolic Diseases, p. I (United States Department of Health, Education and Welfare, Social and Rehabilitation Service, Children's Bureau, 1967)

49. Udenfriend, S., and Cooper, J. R.: The chemical estimation of tyrosine and tyramine. J. Biol. Chem., 196: 227 (1952)

50. Udenfriend, S., and Cooper, J. R.: Assay of L-phenylalanine as phenylethylamine after enzymatic decarboxylation; application to isotopic studies. J. Biol. Chem., 203: 953 (1953).

51. Udenfriend, S., Titus, E., and Weissbach, H.: The identification of 5-hydroxy-3indole acetic acid in normal urine and a method for its assay. J. Biol. Chem., 216: 499 (1955).

52. Völlmin, J. A., Bosshard, H. R., Müller, M., Rampini, S., and Curtius, H. C.: Determination of urinary aromatic acids by gas chromatography. Z. Klin. Chem. Klin. Biochem., 9: 402 (1971).

53. Wegner, E.: Die quantitative Bestimmung der p-oxyphenylbrenztrauben Säure im Harn. Klin. Wochenschr., 28: 347 (1950).

54. Weissbach, H., King, W., Sjoerdsma, A., and Udenfriend, S.: Formation of indole-3-acetic acid and tryptamine in animals. J. Biol. Chem., 234: 81 (1959).

55. Woolf, L. I., Griffiths, R., and Moncrieff, A.: Treatment of phenylketonuria with a diet low in phenylalanine. Brit. Med. J., 1: 57 (1955).

56. Woolf, L. I., Griffiths, R., Moncrieff, A., Coates, S., and Dillistone, F.: The dietary treatment of phenylketonuria. Arch. Dis. Childhood, 33: 31 (1958).

57. Yarbro, M. T., and Anderson, J. A.: L-tryptophan metabolism in phenylketonuria. J. Pediat. 68: 895 (1966)

58. The present address of Dr. F. S. Siegel is Hamaavaq Alley 21, French Hill, Jerusalem, Israel.

59. This work was supported by Research Grant HD 01296 from the National Institute of Child Health and Human Development, National Institutes of Health, United States Public Health Service.

60. Requests for reprints should be addressed to: V. E. Anderson, Ph.D., Dight Institute for Human Genetics, R. 4, Botany Bldg., University of Minnesota, Minneapolis, Minnesota 55455 (USA).

61. Accepted for publication August $15,1975$.

Copyright (c) 1976 International Pediatric Research Foundation, Inc. 